\title{
Fuhrmanolepis dubinskyi n. sp. (Cestoda: Dilepididae) from woodcock Scolopax rusticola (L.) (Aves, Charadriiformes) in Slovakia
}

\author{
J. K. MACKO, V. HANZELOVÁ, V. DUDIŇÁK
}

Parasitological Institute, Slovak Academy of Sciences, Hlinkova 3, 04001 Košice, Slovakia, E-mail: hanzel@saske.sk

\begin{abstract}
Summary
Dilepidid cestode Fuhrmanolepis dubinskyi n. sp. from woodcock, Scolopax rusticola L. in Slovakia is described on the basis of light microscope observations. The new taxon is characterised by medium sized strobila, single crown of ten, 47 - $53 \mu \mathrm{m}$ long "diorchid" (wrench-shaped) rostellar hooks. Genital pores alternate irregularly. Number of testes is $20-30$ and measurements of cirrus-sac and evaginated cirrus reach $176-217 \times 18-31$ and $38-56 \times$ $16-21 \mu \mathrm{m}$, respectively. The uterus is reticular and eggs possess spiny embryophore. $F$. dubinskyi is differentiated from closely related congeneric species and some other morphologically similar dilepidids.
\end{abstract}

Key words: Cestoda; Dilepididae; Fuhrmanolepis dubinskyi n. sp.; Scolopax rusticola; Charadriiformes; Slovakia

\section{Introduction}

The research of the tapeworms from the Dilepididae family, Railliet et Henry, 1909 brings about new information on the species composition and their features in different hosts. The detailed knowledge on morphology of these tapeworms has lead to the establishment of the genus Fuhrmanolepis Spassky et Spasskaja, 1965. Schmidt (1986) later synonymised „Fuhrmanolepis Spasskii et Yurpalova, 1967“" with the genus Dilepis Weinland, 1858. Bona (1994) refused this synonymity, emending the name Fuhrmanolepis to Fuhrmannolepis Spassky et Spasskaya, 1965 and changing the diagnosis of the genus. However, he did not provide enumeration of the species. Due to the discrepancies that have arisen we decided to classify newly described species into the original genus according to the system of Spasskaya and Spassky (1978). Thus the aim of the present article is to provide a description of new Fuhrmanolepis taxon from woodcock Scolopax rusticola (L.). In the 50's and 60's, this host has been relatively abundant in Slovakia, in particular during spring migration (Ferianc,
1977). Pursuant to current legislation (the Code of Laws No. 24/2003), it is regarded as the endangered species of the national importance. $S$. rusticola is of great importance from the helminthological aspect, as it serves as a host for a vast array of cestodes. Data on their species composition were published by Ryšavý and Farkaš (1982).

\section{Materials and methods}

Tapeworms, recovered from the woodcock Scolopax rusticola were examined within the period of $1958-1970$ in Kurov and other localities near Bardejov, north-eastern Slovakia. The specimens were fixed and preserved in alcohol-formaldehyde-acetic acid, stained with Semichon's and Blazhin's acetic carmines, dehydrated in ethanol series, cleared in clove oil and mounted into Canada balsam. They were identified based on species-specific morphological characters on permanent slides. Taxonomically important traits were studied in detail and measured under a microscope linked to a computer with an image analysis software (Olympus analySISdocu) and their measurements were taken by scheme of Mas-Coma and Galan-Puchades (1991). The present descriptions are based on evaluation of tapeworm specimens collected from 15 individuals of $S$. rusticola. Measurements are in micrometers $(\mu \mathrm{m})$ except where indicated.

For comparative purposes, 8 specimens of Fuhrmanolepis slesvicensis (Krabbe, 1882) collected from S. rusticola in Slovakia were also studied.

\section{Results}

Fuhrmanolepis dubinskyi n. sp. Type-host: Scolopax rusticola (L.) (Aves, Charadriiformes, Scolopacidae).

Type-locality: Kurov and other localities in north-eastern Slovakia (Bardejov, Cigel'ka) 
Site of infection: Small intestine.

Prevalence: less frequent (number of specimens not counted due to the missing scolex hooks and other taxonomically significant features).

Type-material: Holotype: complete specimen coll. no. 797/59i. Paratypes: 753/59, 753/59-1, 753/59-3, 797/59-1, 797/59d, 797/59h, 797/59j and 202/61m, 80/69m. Specimens are provisionally deposited at the Parasitological Institute SAS in Košice, Slovakia.

Etymology: The specific name is dedicated to Professor Pavol Dubinský, in recognition to his remarkable contribution to the field of parasitology.

Description [based on 3 complete and 7 incomplete specimens with scoleces and rostellar hooks; Figs. 1-3].

Strobila $25-31 \mathrm{~mm}$ long and up to $1.4 \mathrm{~mm}$ wide. Maximum scolex width 340 at the level of suckers. Suckers rounded or oval $145-183 \times 121-179$ in size, unarmed. Rostellum very long, protrusible up to $203-315$. Apical disc rounded, up to $86-102$ wide, stem narrow $24-41$ in diameter (with severed and twisted retractor? in holotype)
(Fig. 1A). Rostellar pouch elongated, extending to posterior third of suckers. Rostellar hooks resemble "diorchid" (wrench-shaped) type (Figs. 1B, 3B), 10 in number, $47-$ 53 long, spaced in single crown; blade $14-15.5$; base $35-$ 38 , width of hook $10-12$ (Fig. 1B). Development of proglottides protandrous. Mature and gravid proglottides craspedote, wider than long, some of them longer than wide, $298-817 \times 361-911$ (Figs. 1C, D and 2A, B). Genital pores irregularly alternating, situated anteriorly to the middle of lateral proglottis margin. In some proglottides, genital pores are situated in the middle of proglottis side (Fig. 2B). One particular segment possessed genital pore localized in the middle area. Male and female genital ducts between osmoregulatory canals. Ventral and dorsal osmoregulatory canals $13-30$ and 3 wide, respectively.

Testes $20-30$ in number, arranged usually posteriorly to ovary and vitellarium, few testes may lie alongside vitellarium. Fully developed testes round to oval, $62-133$ in size. External vas deferens consists of numerous coils forming inconspicuous aggregation in anterior part of
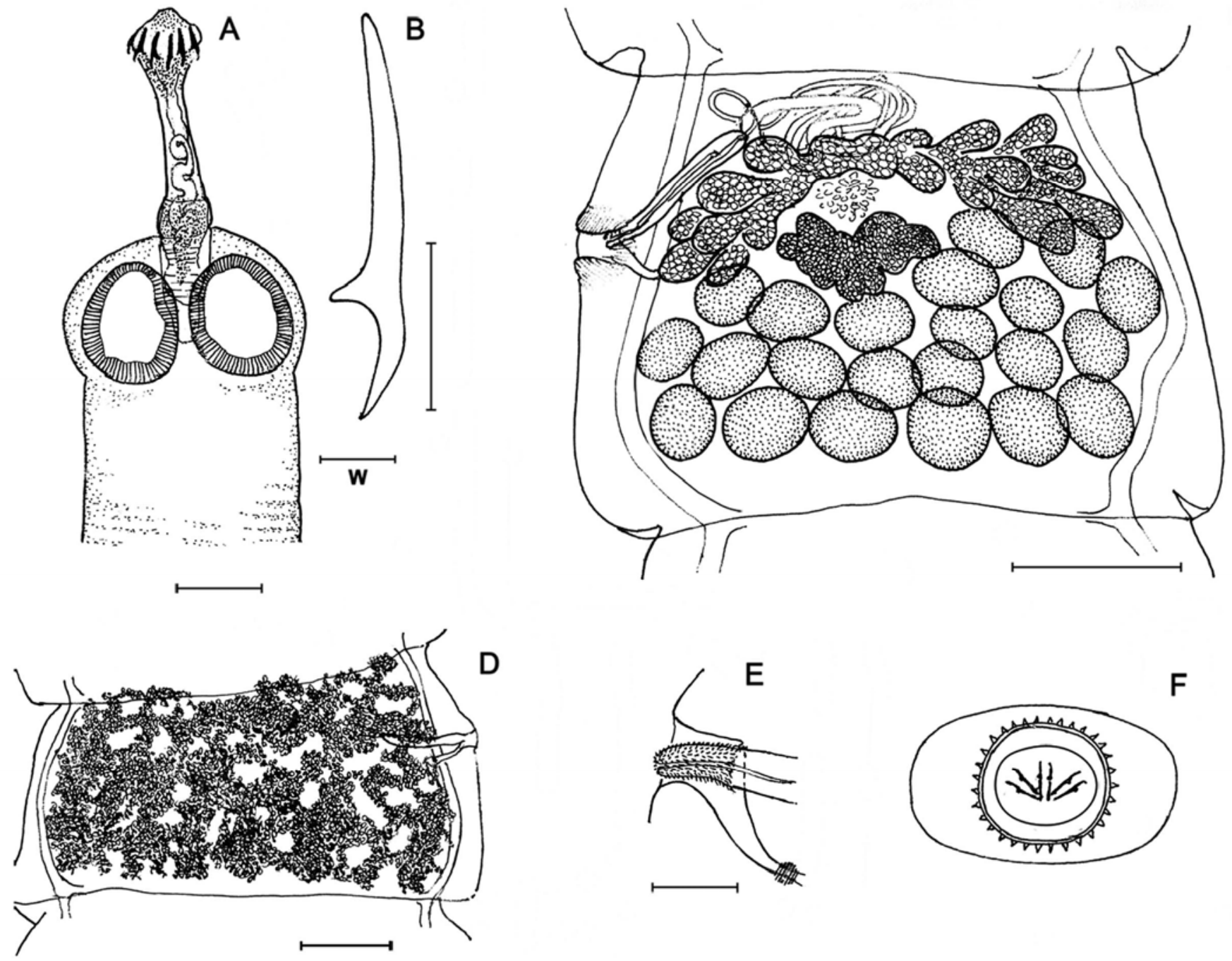

Fig.1. Fuhrmanolepis dubinskyi n. sp. (holotype). A - scolex; B - rostellar hook; C-hermaphroditic proglottis with 22 testes;

D - pregravid proglottis; E - cirrus and F - egg. Scale-bars: A - $100 \mu \mathrm{m} ; \mathrm{B}-20 \mu \mathrm{m} ; \mathrm{C}, \mathrm{D}-200 \mu \mathrm{m} ; \mathrm{E}-40 \mu \mathrm{m} ; \mathrm{F}-\mathrm{sketch}$; w-width of hook. 


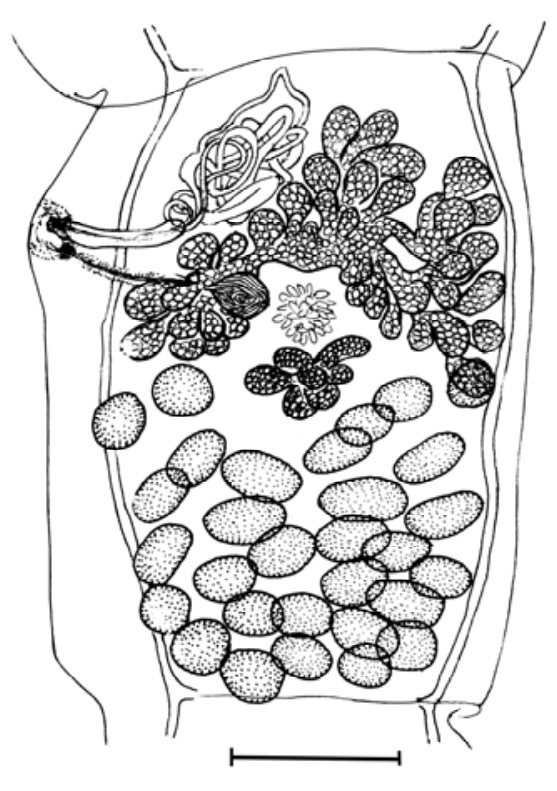

A

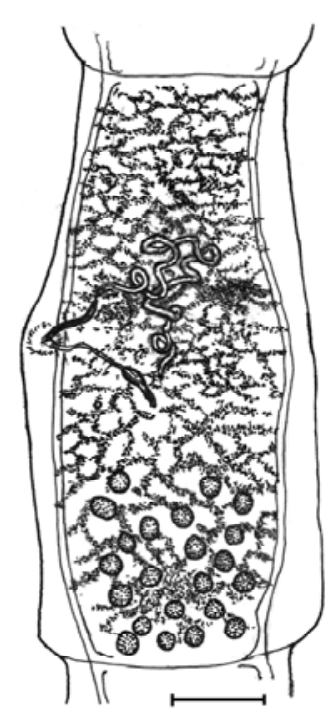

B

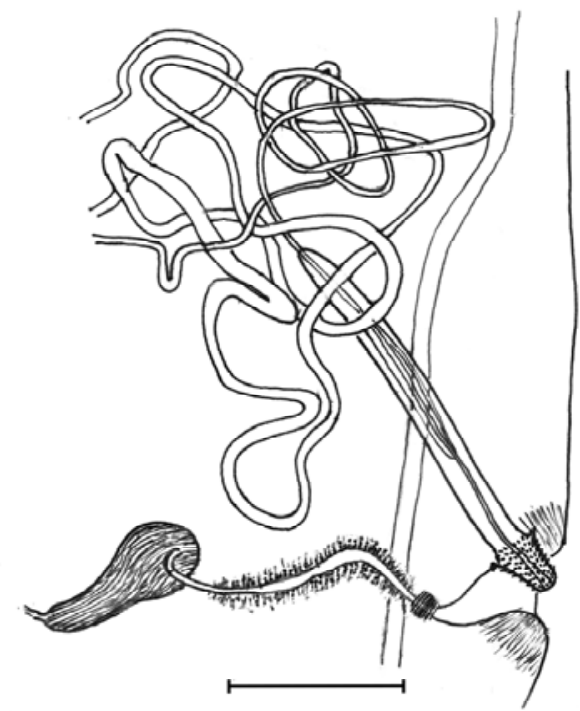

C

Fig. 2. Fuhrmanolepis dubinskyi n. sp. (paratype). A - hermaphroditic proglottis; B - premature proglottis $\mathrm{C}$ - terminal parts of genital ducts with partly evaginated cirrus. Scale-bars: A, B $-200 \mu \mathrm{m} ; \mathrm{C}-100 \mu \mathrm{m}$.

proglottis. Cirrus-sac elongated, thin-walled, $176-217 \times$ $18-31$ in size, reaching to poral third of proglottis and opened into deep genital atrium. Internal vas deferens usually coiled. Evaginated cirrus slightly conical, $38-56$ long; at proximal and distal parts $16-21$ and $10-15$ wide, respectively, armed with tiny needle-shaped spines (Fig. 1E). Spines up to 3 long, irregularly disposed (Fig. 3A).

Female gonads in anterior part of proglottides (Figs. 1C, 2A). Ovary bi-winged, 380 - 746 wide, markedly lobular. Aporal wing usually stronger developed (poral and aporal wing without obvious difference in holotype). Vitellarium lobular, transversely elongated $120-196$ in size, mostly located in central part of proglottis, posterior to ovary. Mehlis' glands distinct, anterior to vitellarium. Seminal receptacle globular, 62 in diameter, otherwise pyriform 96 $-113 \times 41-48$ or oval up to 70 in longer diameter. Vagina passes posterior to cirrus-sac. Vaginal sphincter lessdistinct, $12-14$ in diameter (Figs. 1E, 2C). Developing uterus reticulate (Fig. 1D). In gravid proglottides, uterus filled with eggs occupies almost all-median space. Eggs oval, $45-52 \times 24-31$ without filaments. Embryophore oval $21-29 \times 19-26$, surface seeded with minute triangular spines, about 2 long (Fig. 1F). Spines clearly visible in ripe eggs. Oncosphere $19-22 \times 15-17$. Embryonic hooks $7-8$.

Holotype: $25 \times 1.4 \mathrm{~mm}$. Scolex 288 in diameter. Suckers $145-148 \times 121-131$. Ten rostellar hooks 49 long. Testes 20-24 in number. Cirrus-sac $176-200 \times 21-31$ in size. Cirrus slightly conical 41 long; at proximal part $16-19$ wide. Uterus reticulate. Embryophore spined.
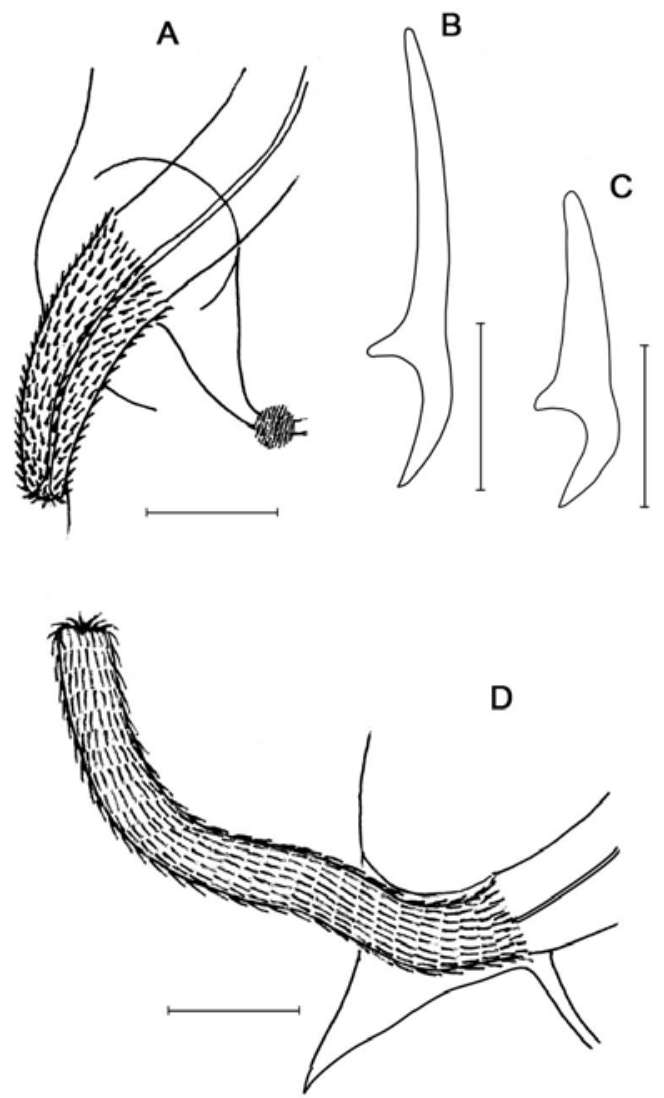

Fig. 3. Rostellar hooks and terminal parts of male genital organs. Fuhrmanolepis dubinskyi n. sp (A, B) and F. slesvicensis (C, D). $\mathrm{A}, \mathrm{D}$ - evaginated cirruses; B, C - rostellar hooks. Scale-bars: A, D $-30 \mu \mathrm{m}$; B, C $-20 \mu \mathrm{m}$. 
Remarks: Fuhrmanolepis dubinskyi n. sp. in particular resembles - considering the size and shape of the hooks Fuhrmanolepis slesvicensis (Krabbe, 1882), described from the same host. Its original description is extraordinarily brief: Uncinulorum circiter 10 longit. $0.041 \mathrm{~mm}$. Habitaculum. Scolopax rusticola, in Slesvico (Friis)" (Krabbe, 1882). The type-material of this species is not yet available (R. Kristensen - personal communication). Base on this description, Matevosyan (1963) and Spasskaya et Spassky (1978) included into this species dilepidids app. 3-14 mm long, with a single crown of 10 hooks, more or less "diorchid" (wrench-shaped) type, $40-42 \mu \mathrm{m}$ long. Hermaphroditic segments contain $10-18$ testes. Relatively long cirrus-sac, reaching to the aporal part of the proglottis includes armed cirrus, $100 \mu \mathrm{m}$ long when protruded. In the $F$. slesvicensis specimens from Slovakia, when fully protruded, the cylindrical cirrus is 134 long and 17 wide at the proximal and $14-15 \mu \mathrm{m}$ at the distal end. The surface of the cirrus is seeded with up to $5 \mu \mathrm{m}$ long spines, arranged consecutively in $9-10$ longitudal rows. $F$. dubinskyi n. sp. differs from the mentioned species in: 1) larger sized hooks (Figs. 3B, C) and strobilae; 2) a higher number of testes, along with different morphology of the genitals; 3 ) a smaller relative length of cirrus-sac (in relation to proglottis width) and 4) a relatively small, slightly conical cirrus armed with irregularly disposed small needle shaped spines. (Figs. 3A, D).

Out of other dilepidids, it is necessary to compare the new species with Paricterotaenia mariae Mettrick, 1958 (Mettrick, 1958), which parasitize in Passeriformes. It also possesses 10 hook of approximately same length (48 - 50 $\mu \mathrm{m})$. It differs from $F$. dubinskyi n. sp. in: 1) the structure of scolex with a shorter stem of rostellum and different shape of hooks' blade; 2) a smaller number of testes (12 $14)$; 3) two winged ovary of tightly packet follicles; 4) saclike uterus and a 5) smooth embryophore.

Other species of dilepidids with a single crown of 10 "diorchid" (wrench-shaped) hooks, classified into other genera (Belogurov and Zueva, 1968; Burt, 1983; Schmidt, 1986; Bona, 1994) possess substantially smaller hooks and different parameters of several taxonomically significant features.

\section{Acknowledgements}

The authors are sincerely grateful to Dr. B. B. Georgiev, from the Central Laboratory of General Ecology, Bulgarian Academy of Sciences, Sofia, Bulgaria for his valuable comments to recent systematics of the genus Fuhrmanolepis and some other genera of Dilepididae. They are also indebted to Dr. A. K. Galkin, Institute of Zoology, St. Petersburg, Russia and Prof. R. Kristensen Zoological Museum, Copenhagen, Denmark for valuable help in providing hardly accessible publications. The study was supported by the Grant Agency of the Slovak Republic VEGA, project No. 2/7192/27 and European Commission's Research Infrastructure Action via the SYNTHESYS Project No. DK-TAF-2354.

\section{References}

Belogurov, O. I., Zueva, L. S. (1968): Two new cestode species of shorebirds from Far East. Soob. Dalnevost. Fil. V. L. Komarova AN SSSR, 26: 11 - 17 (In Russian)

BONA, F. V. (1994): Family Dilepididae Railliet \& Henry, 1909. In: Khalil, L. F., Jones, A., Bray, R. A. (Eds): Keys to the Cestode Parasites of Vertebrates. CAB International, Wallingford, pp. 443 - 554

BURT, D. R. (1983): Taeniarhynchaena micropalamae gen. et sp. n. (Cestoda, Dilepididae) from the stilt sandpiper Micropalama himantopus (Bonaparte, 1826). J. Parasitol., 69: $750-753$

Ferianc, O. (1977): Birds of Slovakia. I. Publ. House Veda, Bratislava (In Slovak)

KrABBE, H. (1882): Nye Bidrag til Kundskab om Fuglenes Baendelorme. Vidensk. Selsk. Skr., 6te Raekke, Naturvidenskabelig og Mathematisk Afd. 1ste Bd VII: 347 - 366 (In Danish)

MASs-ComA, S., Galan-Puchades, M. T. (1991): A methodology for the morphoanatomic and systematic study of the species of the family Hymenolepididae Railliet et Henry, 1909 (Cestoda: Cyclophyllidea). Res. Rev. Parasitol., 51: 139 - 173

Matevosyan, E. M. (1963): Principles of Cestodology. Dilepidoidea - Tapeworms of Domestic and Wild Birds. Izdatel'stvo AN SSSR, Moscow (In Russian)

METTRICK, D. F. (1958): Helminth parasites of Hertforshire birds II. - Cestoda. J. Helminthol., 32: 159 - 194 RYŠAVÝ, B., FARKAŠ, J. (1982): Occurrence of tapeworms in woodcock in Slovakia. Folia Venat., 12: $261-268$ SCHMIDT, G. D. (1986): CRC handbook of tapeworm identification. CRC Press Inc., Boca Raton, Florida

SpasskayA, L. P., SpASSKY, A. A. (1978): Cestodes of Birds in the USSR. Dilepididae of Limnophilous Birds. Izdatel'stvo Nauka, Moscow (In Russian) 